\title{
Stress faced by gifted Vietnamese students: what might contribute to it?
}

\begin{abstract}
BACKGROUND
Gifted students might have to face an abundance of stress. Nevertheless, very little evidence in Vietnam indicates how much stress those students are experiencing and what might predict it. This study aims to examine the stress level in students of the High School for Gifted Students in Hanoi and factors that might contribute to the stress.
\end{abstract}

\section{PARTICIPANTS AND PROCEDURE}

This is a cross sectional study with the participation of 150 students from the High School for Gifted Students, Hanoi. Data were collected from March to April 2015. The first measure was the "Stress Level Test", which was adapted to the Vietnamese culture to measure academic stress in students. The second measure examined factors contributing to stress: 1) social life, 2) family, 3) school work, 4) personal relationships, 5) well-being, 6) adapting skills.

\section{RESULTS}

The results showed that $74.00 \%$ of students were experiencing mild to medium stress, which was found to be higher in girls and in students who lived away from home. The six predicting factors significantly contribute $17.30 \%$ to students' stress experience, of which school work $(p=.001)$ and students' well-being $(p=.011)$ can individually predict stress. These outcomes suggested that more attention should be focused on this specific population and more actions need to be taken to help them perform better at school.

\section{CONCLUSIONS}

Students of the High School for Gifted Students definitely experienced a considerable amount of stress which was related to school pressure and their well-being. For them to have a better high school life, more recreational and leisure time activities outside the classroom need to take place. In addition, more approachable and functional advisors and counseling personnel would be an ideal solution to this problem.

\section{KEY WORDS}

stress; gifted Vietnamese students; well-being; school work

ORgANIZATION - 1: VNU University of Social Sciences and Humanities, Hanoi, Vietnam · 2: Massey University, Auckland, New Zealand

AUthors' Contributions - A: Study design - B: Data collection · C: Statistical analysis - D: Data interpretation .

E: Manuscript preparation - F: Literature search · G: Funds collection

CORRESPonding AUthor - Minh Hang Thi Nguyen, Ph.D., VNU University of Social Sciences and Humanities, Block D,

336 Nguyen Trai, Thanh Xuan, Hanoi, Vietnam, e-mail: minhhangnt@gmail.com

to Cite this ARTicle - Nguyen, M. H. T., Hoang N. P. T., \& Nong, M. T. (2016). Stress faced by gifted Vietnamese

students: what might contribute to it? Health Psychology Report, 4(1), 16-23. doi: 10.5114/hpr.2016.55073

RECEIVED 19.08.2015 REVIEWED 06.09.2015 ACCEPTED 01.10.2015 PUBLISHED 02.11.2015 


\section{BACKGROUND}

Stress can be seen as an unavoidable and essential part of any human's life. It helps the body to increase focus, strength, and alertness to meet a tough situation (Lazarus \& Folkman, 1984). Nevertheless, excessive stress co-occurring with long-term stressful conditions can disrupt one's performance and cause a variety of emotional, behavioral, and physiological problems. Over the years, research has indicated that the effects caused by stress can be very harmful, especially among adolescents, as they experience greater sensitivity towards their surroundings as well as anticipation for doing well (Crystal et al., 1994). For the majority of adolescents, school is an important environment where they develop physically and mentally (Eccles, 2004). However, it can be at the same time a major source of stress for many teenagers (Geisthardt \& Munsch, 1996). As reported by the American Psychological Association, school achievement was one of the top stressors in adolescence reported by youth, which was greater than peer problems or family conflict (American Psychological Association, 2009). That stress is especially intense among those having high academic achievement and those who were trained in a highly competitive environment such as gifted high school or university preparatory programs (Feld \& Shusterman, 2015).

A series of studies investigating the experience of students from elite high schools reported that the students suffered from high levels of stress. The primary source of stress was related to the competitive college application process and heavy academic workloads, while their peers in a typical program reported stressors which were associated with more diverse factors including family, peers, life events, and academic requirements (Bound, Hershbein, \& Long, 2009; Suldo, Shaunessy, Thalji, Michalowski, \& Shaffer, 2009). What is more, while lower grades were associated with more academic stress in elite program students, for the general students, higher levels of stress were associated with higher grades (Suldo et al., 2009).

Like many developing countries, in Vietnam, schooling is widely seen as critical to an individual life. The years of schooling are important to a person's future not only because schooling can ensure them a good life but also because it helps to raise the family reputation and social position (Huy, 2012; Thai $\&$ Falaris, 2014). Because of that significance, keeping their academic performance up high and being well prepared for the University Entry Examinations after graduating from high school are tasks of the utmost importance for Vietnamese children, which creates much pressure for them.

In the past 10 years, many studies have explored the mental health of school age children in Vietnam, and the combined results indicate that children in Viet- nam faced substantial mental health challenges. Tuan et al. (2003) studied child health and development in some developing countries-including Vietnam and found that children experienced a large number of stressors, with $20.00 \%$ of the sample above the cut-off for the study's mental health screening measure. In another study conducted in southern Vietnam, Anh (2007) assessed the mental health functioning of high school students, and found that $16.00 \%$ were above the threshold for experiencing significant affective problems. In northern Vietnam, Hoang-Minh and Tu (2009) also reported that about $25.00 \%$ of adolescents in their sample were at or above the clinical cutoff on at least one Child Behavior Checklist Scale. In 2011 and 2012, there were two studies conducted by Thuy (2011) and Hang (2012) proposing that beside mental health problems, what is more common among Vietnamese school-age children is school-related stress. It was found that more than $47.00 \%$ of students in senior years of high school in Hanoi experience stress at different levels. This stress is greater in students from a gifted high school $(82.90 \%)$ and has a close relation to academic requirements and school workload (Hang, 2012; Thuy, 2011).

The above evidence provides a glimpse into the seriousness of Vietnamese children's mental health problems. However, while most of the studies described the stress experience well, none of them clearly identify factors possibly contributing to gifted students' stress. In addition, it is suggested that more attention needs to be directed to the gifted high school students as they may be most vulnerable to stress. This study has three purposes. First, it is essential to verify previous findings on gifted students and stress. Second, as little was known about this phenomenon in Vietnam, it is useful to understand the relation between school stress and student's demographics. The review of the literature indicated the correlation between gifted students' stress and demographic characteristics including gender, grade, academic achievements and living arrangements (Geisthardt \& Munsch, 1996; Hang, 2012; Karatzias, Power, Flemming, Lennan, \& Swanson, 2002; Misra \& McKean, 2000; Rollins \& Cross, 2014; Shaunessy \& Suldo, 2009; Suldo, Shaunessy, \& Hardesty, 2008; Thuy, 2011). In this study, the relationship between stress score and those demographics variables will be tested to determine whether the effect has a role in a Vietnamese context. Finally, this study attempts to discover factors that contribute to the experience of stress among gifted Vietnamese students.

To address these goals, we organized our study around three major questions:

1. How stressed are students of the High School for Gifted Students?

2. Which demographic factors have a significant correlation with students' stress?

3. Which factors contribute to students' stress?
Stress of Vietnamese gifted students 


\section{PARTICIPANTS AND PROCEDURE}

This is a cross sectional study of 150 students from the High School for Gifted Students, evenly distributed among grades. Over half (51.30\%) are male, $48.70 \%$ are female. Most of them come from other provinces (60.70\%); only $39.30 \%$ have their family living in Hanoi.

Participants in this research are students of High Schools for Gifted Students in the following areas: Mathematics, Physics, Chemistry, and Computer Sci-
Minh Hang Thi Nguyen, Nam Phuong Thi Hoang, Men Thi Nong ence. There are only two such schools in Hanoi. In order to attend those schools, every student has to pass a very difficult entrance exam specialized for each area. Only excellent students in secondary school register for these high schools, and approximately $5-10 \%$ of those who register pass. During their study, students have to achieve excellent academic results and pass difficult exams. Those who fail the criteria will be forced to transfer to normal high schools in Hanoi, or in the local area where their family live.

Data were collected during March and April 2015. Researchers approached students to explain the study and obtain their agreement to participate. Names were never collected to ensure confidentiality.

The study package includes two measures. The first one is called the "Stress Level Test". The original version of this scale was used to measure stress at work (Nikiforov, 2007). This scale was then adapted to the Vietnamese culture by lecturers of the Faculty of Psychology, University of Social Sciences and $\mathrm{Hu}-$ manities, Hanoi to measure academic stress in students. It has 22 items that evaluate students' affective issues and behaviors in relation to academic environment. Cut-off scores were set for four level of stress: - 0-15: no stress found;

-16-30: mild stress. With mild stress, although students might feel the pressure, they can still function normally in daily life and maintain their social network;

- 31-45: medium stress. With medium stress, the individual starts to present some physical problems such as: feeling tired, having no joy studying, and over-concern with their performance;

- 46-60: severe stress. At the severe level, the individual starts to experience some clinical symptoms of depression such as loss of energy, weight loss, inability to sleep, sadness, anxiety, and irritability.

Cronbach's $\alpha$ coefficient employed to assess the internal consistency of the "Stress Level Test" showed that this test had good reliability. The calculation based on 150 cases showed a Cronbach's $\alpha$ value of .85 . Though it has been adopted in a number of studies in Vietnam, this is the first study to report evidence regarding psychometric properties of the Vietnamese version of the test.

For factors contributing to stress, we adopted factors suggested by Hang (2012). According to Hang, there were four factors that might have a significant correlation with Vietnamese students' stress. Those factors were selected to be tested in this study: 1) socialization (e.g.: I feel isolated), 2) family (e.g.: $M y$ parents have too much expectation for me), 3) personal relationships (e.g.: I've just broken up with my boyfriend/girlfriend) and 4) well-being (e.g.: I feel unconfident when I'm in class). Two other factors found to associate with students' stress throughout the literature - 5) adapting skills (e.g.: I quickly adopt an appropriate studying strategy) and 6) school work (e.g.: I have too much homework that I can barely finish) were also added to the list (Feld \& Shusterman, 2015; Geisthardt \& Munsch, 1996). All six factors were represented through 76 items. The calculation of reliability also indicated that this measure had good psychometric properties with Cronbach's $\alpha$ of the whole scale being .91 and that of each scale ranging from .85 to .96 .

\section{RESULTS}

\section{DEMOGRAPHICS}

The demographic data for this cohort are presented in Table 1 . Over half $(51.30 \%)$ of the sample were male, and $48.70 \%$ were female. They were evenly distributed among three grades. A majority of students come from other cities (61.70\%). More than half of the participants $(65.30 \%)$ received a Distinction for their academic excellence in the last semester; $34.70 \%$ were categorized as Good and no one report to have a Pass grade.

\section{STRESS LEVEL}

It was found that $111(74.00 \%)$ out of 150 gifted students in this study experienced mild or medium stress, of which mild stress constituted a large part with 89 cases $(59.30 \%)$; $22(14.70 \%)$ students experienced medium stress; 39 (26.00\%) students reported no stress; and no student indicated severe stress (see Table 2 for more details). This finding was comparable with other studies about stress levels of Vietnamese students. A study that examined stress in 65 senior students from the High School for Gifted Students, Hanoi University of Languages also indicated that a large number of students $(89.20 \%)$ reported to have experienced stress (Thuy, 2011).

\section{STRESS AND DEMOGRAPHIC VARIABLES}

Table 3 reports stress scores in the different demographic groups of gifted students. The mean score of the $10^{\text {th }}$ graders $(M=23.22, S D=9.06)$ was higher 
Table 1

Demographic characteristics of participants

\begin{tabular}{lccc}
\hline & Category & $n$ & $\%$ \\
\hline \multirow{2}{*}{ Gender } & Male & 77 & 51.30 \\
& Female & 73 & 48.70 \\
Grade & $10^{\text {th }}$ & 50 & 33.30 \\
& $11^{\text {th }}$ & 50 & 33.30 \\
City of origin & $12^{\text {th }}$ & 50 & 33.30 \\
& Hanoi & 59 & 39.30 \\
Academic achievement & Others & 91 & 60.70 \\
& Distinction & 98 & 65.30 \\
& Good & 52 & 34.70 \\
\hline
\end{tabular}

Table 2

Level of stress reported by students of the High School for Gifted Students

\begin{tabular}{lrr}
\hline Stress level & $n$ & $\%$ \\
\hline No stress $(\leq 15)$ & 39 & 26.00 \\
Mild stress $(16-30)$ & 89 & 59.30 \\
Medium stress (31-45) & 22 & 14.70 \\
Severe stress $(>45)$ & 0 & 0.00 \\
Total & 150 & 100.00 \\
\hline
\end{tabular}

than the $11^{\text {th }}(M=20.22, S D=8.62)$ and $12^{\text {th }}$ graders $(M=20.80, S D=8.06)$. Nonetheless, the analysis of variance with post-hoc comparison using Tukey's HSD test showed no difference between the grades and the stress score $(F(3,146)=1.71, p=.184)$.

A $t$-test conducted for students' gender on their stress score showed a trend toward significance between male and female students in their stress score $(p=.061)$, of which girls reported a higher level of stress than boys. This finding was consistent with the literature, indicating that female students across levels of studying experienced more stress than their male counterparts (Hang, 2012; Thuy, 2011).

When being compared using the $t$-test, the province of origin showed a significant effect on students' stress. Gifted students who originally came from a province other than Hanoi $(M=22.85, S D=8.55)$ experienced more stress than those who lived with their families in Hanoi $(M=19.18, S D=8.34)$, $t(148)=-2.61, p=.011$.

As all students reported to be graded with a Distinction and Good for their academic achievement in the last semester, the Pass category was discarded from the analysis, leaving two groups. The $t$-test conducted for the stress score in the group with a Dis-
Table 3

Stress differences in terms of demographics

\begin{tabular}{lccccc}
\hline & & $M$ & $S D$ & $t / F$ & $p$ \\
\hline \multirow{4}{*}{ Grade } & 10 & 23.22 & 9.06 & 1.71 & .184 \\
& 11 & 20.22 & 8.62 & & \\
Gender & Male & 20.12 & 6.83 & -1.89 & .061 \\
& Female & 22.76 & 10.06 & & \\
Province & Hanoi & 19.18 & 8.34 & -2.61 & .011 \\
& Others & 22.85 & 8.55 & & \\
$\begin{array}{l}\text { Academic } \\
\text { achieve- } \\
\text { ment }\end{array}$ & Good & 22.10 & 8.60 & 1.35 & .186 \\
\hline
\end{tabular}

tinction and the Good one showed no significant difference. No difference of stress score was found for academic achievement $(t(148)=1.35, p=.186)$.

\section{FACTORS PREDICTING STUDENT STRESS}

Factors contributing to stress were indicated by a questionnaire of 76 items asking about 6 areas: social life, family, school work, personal relationships, well-being and adapting skills.

A summary of the regression model is presented in Table 4. The group of 6 factors was a significant predictor for student stress $\left(R^{2}=.17, F(6,143)=4.98\right.$, $p<.001)$; it accounted for $17.30 \%$ of the variance. Among those factors, school work $(\beta=.34, t=3.39$, $p=.001)$ and well-being $(\beta=.24, t=2.59, p=.011)$ were the best predictors for student stress.
Stress of Vietnamese gifted students 
Table 4

Factors contributing to students' stress

\begin{tabular}{|c|c|c|c|c|c|c|}
\hline & \multirow[t]{2}{*}{$R^{2}$} & \multirow[t]{2}{*}{$R^{2} \Delta$} & \multicolumn{2}{|c|}{$\begin{array}{c}\text { Unstandardized } \\
\text { coefficients }\end{array}$} & \multicolumn{2}{|c|}{$\begin{array}{l}\text { Standardized } \\
\text { coefficients }\end{array}$} \\
\hline & & & $B$ & $S E$ & $\beta$ & $p$ \\
\hline & .17 & .17 & & & & $<.001$ \\
\hline Social life & & & -1.46 & 2.17 & -.08 & .505 \\
\hline Family & & & -2.37 & 2.32 & -.14 & .309 \\
\hline School work & & & 10.86 & 3.20 & .34 & .001 \\
\hline Personal relationship & & & -1.27 & 1.62 & -.08 & .434 \\
\hline Well-being & & & 3.48 & 1.34 & .24 & .011 \\
\hline Adapting skills & & & 0.21 & 2.32 & .01 & .927 \\
\hline
\end{tabular}

\section{DISCUSSION}

Students in elite academic environments are often thought of as a "low risk" group. Nevertheless, in the last two decades, a rich body of scientific evidence has indicated that gifted and high-achieving youngsters have been under potential harm arising from prolonged stress. Studies have described that environment as "hotbeds of pressure and stress" (Galloway, 2012) and indicated that gifted adolescents are likely to be subjected to high workloads and expectations (Shaunessy \& Suldo, 2009; Suldo et al., 2008).

Though this is a well-developed research topic worldwide, stress in gifted students is quite a new area in Vietnam. To date, there has been only one study exploring the experience of stress in gifted students, by Thuy in 2009 . In that study, $49.00 \%$ of students reported severe stress, and the other $51.00 \%$ also found themselves to experience mild to medium stress. This current study is comparable with Thuy's study by indicating that a significant amount of students at the High School for Gifted Students perceive themselves as stressed at one time or another. However, the percentage of students who reported with stress is lower in this study than Thuy's one. This might be due to the characteristic differences of the sample. The proportion of females in Thuy's study (96.00\%) was higher than that of the current study $(48.70 \%)$. As it is widely known that females are more vulnerable to stress than males, it is reasonable that the proportion of stress reported by Thuy is higher than in the present study.

It was also found that students who lived away from their families experienced more stress than those lived with family in Hanoi. To live away from home at 16 years of age means that these youths have to face many challenges including a new living environment, new academic expectations, and especially new relationships. This finding was supported by a study conducted in 2004. The researchers found that students who lived in dorms/rental houses also reported more stress than those living with their families. They complained of not having a good studying environment (too noisy), and the living cost is also an issue (Shaikh et al., 2004).

For more detail, we randomly interviewed some $10^{\text {th }}$ grade students. Students said that since having started their studying, they had to move into the school dorm. Everything seemed so new to them and they had to live on their own, which they had never experienced when living at home. It is necessary to mention that in Vietnamese culture, authoritarian and controlling parenting styles are widely adopted (Herz \& Gullone, 1999). These parenting styles have their own values in this context to keep their children successful at school. Nevertheless, it creates a young generation that lacks independence and autonomy (Chao, 2001; Herz \& Gullone, 1999; Nguyen, 2008; Okagaki, 2001). Therefore, when having to live on their own and have to take responsibility for taking care of themselves, many of them encounter difficulties.

A tendency for girls to show more inclination towards stress than boys was found in this study. This finding is consistent with the literature. A study published in 2002 by Brooks and colleagues indicated that gender might be a major factor to explain stress and that female students were three times more stressed than their counterparts (Brooks, Harris, Thrall, \& Woods, 2002). Thuy (2011) investigated stress for undergraduate students, and also found that Vietnamese female students are more vulnerable to stress than male students.

Many studies in Caucasian populations have reported a relationship between lower school marks and higher burnout levels. In this study, no significant correlation was found between these two variables. This is not the first study to find no significant relationship between stress and academic achievement. A study conducted with over one thousand students from China, Japan, and America also reported that while academic achievement proved to be a significant predictor for stress in American students, it did 
not show any effect on Chinese and Japanese students (Crystal et al., 1994). However, it is worth mentioning that while stress was known to associate with low academic results, in this study, no student was identified with a low school grade. Over half $(65.30 \%)$ had a distinction score; the other $34.70 \%$ also had a good score. The gap between Good and Distinction categories may not be great enough to have a significant effect on students. More studies with a bigger sample size are necessary to refine this finding.

One may expect that youths at the junior year of high school would experience higher pressure from peers, teachers, and family (Erikson, 1997; Greenfield, 1994). However, in this study, we did not find any significant relationship between students' batch and their stress score. This difference might be due to the fact that this study was conducted around the end of the school years, so most of the junior students were no longer strange to the environment; they somehow found a way to adapt to the new studying requirements and method. However, as the sample size of this study was considerably small, more studies with larger samples need to be carried out in the future to confirm this study's findings.

When using a regression model to explore factors contributing to gifted students' stress, it was found that the pressure from school work and the students' well-being are the two most important factors that might contribute to students' stress. This finding was supported by a series of studies conducted both in typical adolescents and gifted ones. In a longitudinal study by Salmela-Aro, Kiuru, and Nurmi in 2008, it was found that there was a significant relationship between depressive symptoms of the students and their experience of stress. A study by Bound et al. (2009) meanwhile showed a significant contribution of school work to stress in talented students. More closely, studies of Hang (2012) and Thuy (2011) also suggested a similar outcome. In Vietnam, the education system was built around the students' ability to memorize knowledge, and the school workload is considerable, which makes it hard for students to acquire all the knowledge within school time and they have to use private tutors as a necessity (Dang, 2011; Phu, 2013). Especially for students of gifted high schools, besides having to master the topics required by the Ministry of Education and Training, they also need to handle the extra workload set by the school, which might double their pressure and exacerbate their stress. Nevertheless, there have been no counseling services in these schools to help those students, so the situation is left unsolved (Hoang-Minh \& Tu, 2009).

\section{CONCLUSIONS}

High school life is beautiful and memorable but it can also be stressful, which may affect not only students' academic performances but also other aspects of life. These effects could remain throughout the three years of high school and even later on (World Health Organization, 1993). Students from a gifted high school definitely experienced a considerable amount of stress related to workload pressure and their well-being. For them to have a better high school life, more recreational and leisure time activities outside the classroom need to take place. Recreational activities such as sports and socialization are crucial for individual growth and personal development (Misra $\&$ McKean, 2000). In addition, more approachable and functional advisors and counseling personnel would be an ideal solution for this problem. These support activities need to be directed closely toward the student life inside and outside the classroom, especially for those living away from home and freshman students, who are most vulnerable to stress. Study skill courses, such as time management, positive self-talk, and stress management techniques, might be helpful with these young people. These skills, if gained early in the first year of high school, may better assist students in dealing with stress due to study loads.

This is one of the few studies examining the stress in gifted high school students in Vietnam and can be seen as one of the first studies to reveal factors contributing to stress in gifted Vietnamese students. There were some limitations that need to be considered when interpreting the study results: the small sample size of participants from a single high school of gifted students and the fact that the measure is not widely used in other Western studies, which makes it hard to compare and contrast between different populations. In the future, more studies need to be conducted on this topic to extend the knowledge in Vietnam in particular and Asia in general.

\section{ACKNOWLEDGEMENTS}

We would like to express our gratitude to the High School for Gifted Students in Hanoi for fully supporting us during data collection, and we also want to thank our anonymous participants for willingly taking part in this study. Without them, this manuscript could not exist.

\section{References}

American Psychological Association. (2009). Increasing access and coordination of quality mental health services for children and adolescents.

Anh, H. (2007). Social and behavioral problems among high school students in Ho Chi Minh City. Research findings from the Vietnam Children's Mental Health Research Training Program (pp. 111-196). Hanoi: Educational Publishing House.
Stress of Vietnamese gifted students 
Bound, J., Hershbein, B., \& Long, B. T. (2009). Playing the admissions game: student reactions to increasing college competition. The Journal of Economic Perspectives, 23, 119-146.

Brooks, T. L., Harris, S. K., Thrall, J. S., \& Woods, E. R. (2002). Association of adolescent risk behaviors with mental health symptoms in high school students. Journal of Adolescent Health, 31, 240-246.

Chao, R. K. (2001). Extending research on the consequences of parenting style for Chinese Americans and European Americans. Child Development, 72, 1832-1843.

Minh Hang Thi Nguyen,

Nam Phuong Thi Hoang, Men Thi Nong

Crystal, D. S., Chen, C., Fuligni, A. J., Stevenson, H.W., Hsu, C. C., Ko, H. J., Kitamura, S., \& Kimura, S. (1994). Psychological maladjustment and academic achievement: a cross-cultural study of Japanese, Chinese, and American high school students. Child Development, 65, 738-753.

Dang, H.-A. (2011). A bird's-eye view of the private tutoring phenomenon in Vietnam. IIAS Newsletter, 56, 26-27.

Eccles, J. S. (2004). Schools, academic motivation, and stage-environment fit. Handbook of Adolescent Psychology, 2, 125-153.

Erickson, F. (1996). Going for the zone: The social and cognitive ecology of teacher-student interaction in classroom conversations. In: D. Hicks (ed.), Discourse, learning, and schooling (pp. 29-62). Cambridge: Cambridge University Press.

Feld, L. D., \& Shusterman, A. (2015). Into the pressure cooker: Student stress in college preparatory high schools. Journal of Adolescence, 41, 31-42.

Galloway, M. K. (2012). Cheating in advantaged high schools: Prevalence, justifications, and possibilities for change. Ethics \& Behavior, 22, 378-399.

Geisthardt, C., \& Munsch, J. (1996). Coping with school stress: A comparison of adolescents with and without learning disabilities. Journal of Learning Disabilities, 29, 287-296.

Greenfield, P. M. (1994). Independence and interdependence as developmental scripts. In: P. M. Greenfield \& R. R. Cocking (eds.), Cross-cultural roots of minority child development (pp. 1-40). Hillsdale, NJ: Erlbaum.

Hang, D. T. L. (2012). Factors contribute to school stress and coping style of Vietnamese adolescents. Vietnamese Journal of Psychology, 7, 20-26.

Herz, L., \& Gullone, E. (1999). The relationship between self-esteem and parenting style a cross-cultural comparison of australian and vietnamese Australian adolescents. Journal of Cross-Cultural Psychology, 30, 742-761.

Hoang-Minh, D., \& Tu, H. (2009). The mental health of secondary students in Hanoi and the need for school counseling. Vietnamese Journal of Social Sciences and Humanities, 25, 11-16.

Huy, V. Q. (2012). Determinants of educational expenditure in Vietnam. International Journal of Applied Economics, 9, 59-72.
Karatzias, A., Power, K., Flemming, J., Lennan, F., \& Swanson, V. (2002). The role of demographics, personality variables and school stress on predicting school satisfaction/dissatisfaction: Review of the literature and research findings. Educational Psychology, 22, 33-50.

Lazarus, R. S., \& Folkman, S. (1984). Stress. Appraisal, and coping. New York: Springer.

Misra, R., \& McKean, M. (2000). College students' academic stress and its relation to their anxiety, time management, and leisure satisfaction American Journal of Health Studies, 16, 41-51.

Nguyen, P. V. (2008). Perceptions of Vietnamese fathers' acculturation levels, parenting styles, and mental health outcomes in Vietnamese American adolescent immigrants. Social Work, 53, 337-346.

Nikiforov, G. S. (ed.). (2007). Health Diagnostic. Psychological practice. Saint-Peterburg: Rech Publishers.

Okagaki, L. (2001). Parental beliefs, parenting style, and children's intellectual development. In: E. L. Grigorenko (ed.), Family environment and intellectual functioning: A life span perspective (pp. 141-172). Mahwah, NJ: Lawrence Erlbaum Associates Publishers.

Phu, P. (2013). Where is Vietnamese educational system? The development policies. Journal of Development and Intergration, 9, 56-63.

Rollins, M. R., \& Cross, T. L. (2014). Assessing the psychological changes of gifted students attending a residential high school with an outcome measurement. Journal for the Education of the Gifted, 37, 337-354.

Salmela-Aro, K., Kiuru, N., \& Nurmi, J. E. (2008). The role of educational track in adolescents' school burnout: A longitudinal study. British Journal of Educational Psychology, 78, 663-689.

Shaikh, B. T., Kahloon, A., Kazmi, M., Khalid, H., Nawaz, K., Khan, N., \& Khan, S. (2004). Students, stress and coping strategies: a case of Pakistani medical school (pp. 1357-6283). From Abingdon-carfax publising Limited.

Shaunessy, E., \& Suldo, S. M. (2009). Strategies used by intellectually gifted students to cope with stress during their participation in a high school International Baccalaureate program. Gifted Child Quarterly, 54, 127-137.

Suldo, S. M., Shaunessy, E., \& Hardesty, R. (2008). Relationships among stress, coping, and mental health in high-achieving high school students. Psychology in the Schools, 45, 273-290.

Suldo, S. M., Shaunessy, E., Thalji, A., Michalowski, J., \& Shaffer, E. (2009). Sources of stress for students in high school college preparatory and general education programs: Group differences and associations with adjustment. Adolescence, 44, 925-948.

Thai, T. Q., \& Falaris, E. M. (2014). Child schooling, child health, and rainfall shocks: Evidence from 
rural Vietnam. Journal of Development Studies, 50, 1025-1037.

Thuy, L. T. T. (2011). School stress and coping style of senior highschool students. Vietnamese Journal of Psychology, 4, 22-27.

Tuan, T., Lan, P. T., Harpham, T., Huong, N. T., Thach, T. D., Tod, B., Dua, T. T. \& Ha, N. T. V. (2003). Young Lives Preliminary Country Report: Vietnam.

World Health Organization. (1993). The health of young people: A callenge and a promise. World Health Organization. (1993). The health of young people: A challenge and a promise. Geneva: World Stress of Health Organization. 